\title{
Biophysical educational experiment: science and goodwill in Latin America and Africa
}

\author{
Marcelo M. Morales • Cristobal G. dos Remedios
}

Received: 12 July 2011 / Accepted: 21 July 2011 / Published online: 9 August 2011

(C) International Union for Pure and Applied Biophysics (IUPAB) and Springer 2011

In the 1990's the International Union for Pure and Applied Biophysics (IUPAB) decided, conceptually at least, that the time had come to acknowledge that Africa would one day emerge as a global scientific power, much as it had once dominated the fields of science and medicine. In October 2008, the International Council for Science (ICSU) held its General Assembly in Maputo, Mozambique. Many thought it was a bold, even risky, move to hold its triennial meeting in Sub-Saharan African. In the end there was enthusiastic acclaim for the venture. Of course, ICSU was trying to

Drs. Morales and dos Remedios are presenting this editorial dealing with an important aspect of one of the missions of IUPAB, the promotion of education in Biophysics. I want to thank them both for this initiative and specially for having given four African students the possibility to express themselves.

Jean Garnier

Editor-in-Chief

\author{
M. M. Morales · C. G. dos Remedios \\ Councilors of the International Union for Pure \\ and Applied Biophysics, \\ Sydney, Australia \\ C. G. dos Remedios \\ e-mail: dosremedios@iupab.org \\ M. M. Morales \\ Federal University of Rio de Janeiro, \\ Rio de Janeiro, Brazil \\ C. G. dos Remedios ( $\square)$ \\ The University of Sydney, \\ Sydney, Australia \\ e-mail: crisdos@anatomy.usyd.edu.au
}

underscore its belief that science needed to be fostered in Africa. It had already established a Regional Office for Africa (ROA) in Pretoria under the very able direction of Sospeter Mohongo.

If history is any indication, the African continent has a longer educational history than Europe. In 859 AD, the University of Al Karaouine in Fes, Morocco is recognized as the oldest academic degree-granting university in the world. Morocco also claims to have operated the world's oldest purpose-built hospital with its wide verandahs and multistorey construction. North African mathematicians formed the basis of the architecture that dominated the architecture for centuries. Today, South Africa is in the vanguard of advances in astronomy. While it is not our intention to review the science and technology of all 53 African nations, it is clear there is a huge potential for countries in the African continent to contribute to global science.

African nations like Mozambique realize the potential to use science to overcome economic difficulties. During the ICSU General Assembly in 2008, one of us had the opportunity to meet with H.E. Venancio Massinge, the Minister for Science, who gave the clear impression that his Government saw science as an essential component of his country's economic independence. However, the former colonists of Africa had not left a strong track record of training in science, so now the question is: can countries like Mozambique muster the resources, particularly the human resources to discover and/or adapt the science to suit local conditions?

The complexity of the challenges faced by countries in Africa to rebuild their science and technology demanded an integrative approach to finding feasible solutions to develop 
biophysics on the African continent. One aspect of this is the development of a cooperative approach to sharing scarce resources and expertise among the many nations in Africa. In the 1990's IUPAB had unsuccessfully attempted to initiate biophysics workshops in Africa. Perhaps our timing was off, but it was certainly difficult to obtain agreement for funding, exchange and cooperation.

It was in this context that ICSU provided a grant of Euro30,000 to IUPAB to do an educational experiment. Rather than taking a few expert biophysicists to a workshop in Africa, we proposed to do the reverse.

With support of IUPAB, ICSU, Brazilian Federal Government scientific foundations (CAPES and CNPq), and the State of Rio de Janeiro Research Foundation (FAPERJ) we decided to use the funds for the transport and local support a small number of African students to attend a large course in basic biophysics. It was attended by 410 students from Latin America and was presented by global experts, mainly from Latin America. The course was part of the successful regional postgraduate biophysics programs (the Latin American Postgraduate Program of Biophysics - POSLATAM) that had been operating since 2008 .

\section{IUPAB, LAFeBS and POSLATAM}

Today the program is organized by the Latin American Federation of Biophysical Societies (LAFeBS) and IUPAB. The POSLATAM operation is currently coordinated by Dr. Marcelo Morales who is also the President of LAFeBS. To date, 33 institutions participate in the program, and although membership is dominated by Brazil and Argentina (18 institutions from Brazil, 12 from Argentina), other members represent universities in Uruguay, Colombia and Venezuela. Under the POSLATAM organization, a student enrolled in one university can move to other institutions within the group that have special facilities or expertise needed for the research. Usually this does not involve extended periods away from the students' home campuses. They are comparatively short periods and result in the development of crucial research data needed to complete their degrees and diplomas. Once they return to their original institution they are deemed to have fulfilled all the requirements of that university. The Academic Committee of the program reviews the activities to be undertaken in relation to the $\mathrm{PhD}$ or Master of Science programs in biophysics, but it also considers the interest of the candidates and provides any necessary advice. The activities can be done in any of the enrolled institutions determined by the most appropriate place for any given research activity, including the development of their theses.

\section{The third Latin American postgraduate program of biophysics courses and the first Brazil-Africa colloquium of biophysics}

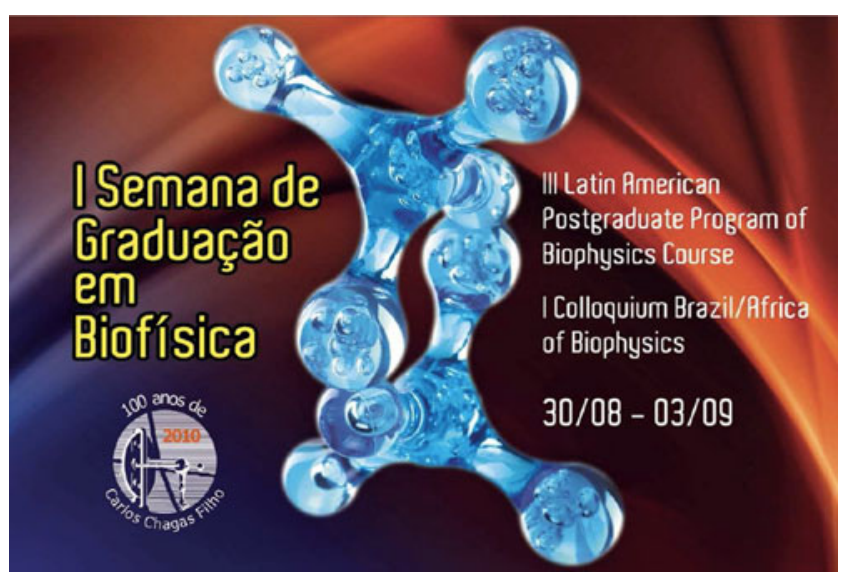

A requirement for participation in the program is that students attend at least one common activity (an annual course or workshop) organized by the Program. In 2010 we held a very special POSLATAM course. Approximately 410 students attended the course, and 120 posters were presented by students in two sessions full of scientific discussion that really integrated the students from different countries especially the African students. Together with IUPAB, LAFeBS, ICSU and the ROA, we were able to fund nine students from South Africa, Kenya, Morocco, Zimbabwe, Uganda, Mozambique, and Ethiopia.

It was a truly groundbreaking event. However, we were taken a bit by surprise at the number of obstacles, difficulties and challenges that had to be dealt with. The organization of transport, particularly visas to Brazil, was very difficult. Visa for travel from some African countries involved transiting through several other countries each with their restrictions. Difficulties in cross-border licensing and payment, and other challenges were completely overcome by a dedicated organization.

We soon realized that we had to make special arrangements for our Africa visitors, one of which was to provide a simultaneous translation of all lectures. The workshop program covered different aspects of basic biophysics including membrane transport, protein structure, molecular 
modeling and dynamics, membrane biophysics, and environmental biophysics. There was a strong emphasis on the relationship between university and industry and on the interface between biochemistry and biophysics.

We also incorporated into the program a one-week individual "internship" in biophysics research labs at the Federal University of Rio de Janeiro. The students were able to follow experiments in different laboratories performed by Brazilian PhD students under the supervision of the heads of laboratories. This experience exited the students from Africa because it provided first hand experience and insight into the processes and practice of science.

There was a two-way interaction between the Latina American and African students that was enjoyed on both sides. We believe the cultural proximity between the two continents assisted this interaction. Language was not problem for the African students, since from both sides of the Atlantic spoke English. In addition, two of the African students were from Portuguese-speaking Mozambique so they had no trouble communicating with the local students. It was evident that the Latin American research students enjoyed the experience the experience every bit as much as the African students and it is very likely that longer term collaborations will follow between POSLATAM and postgraduate programs in Africa.

Much of the above subjective opinion is reinforced by the comments of the African students themselves. At the end of the 2 week program, all students were required to complete a survey of their experiences. The following comments were extracted from the survey responses. Below is a photograph of Professor Marcelo Morales (front left) with the nine students from Africa, and some of the colloquium speakers taken during the Latin AmericanAfrican postgraduate biophysics colloquium.

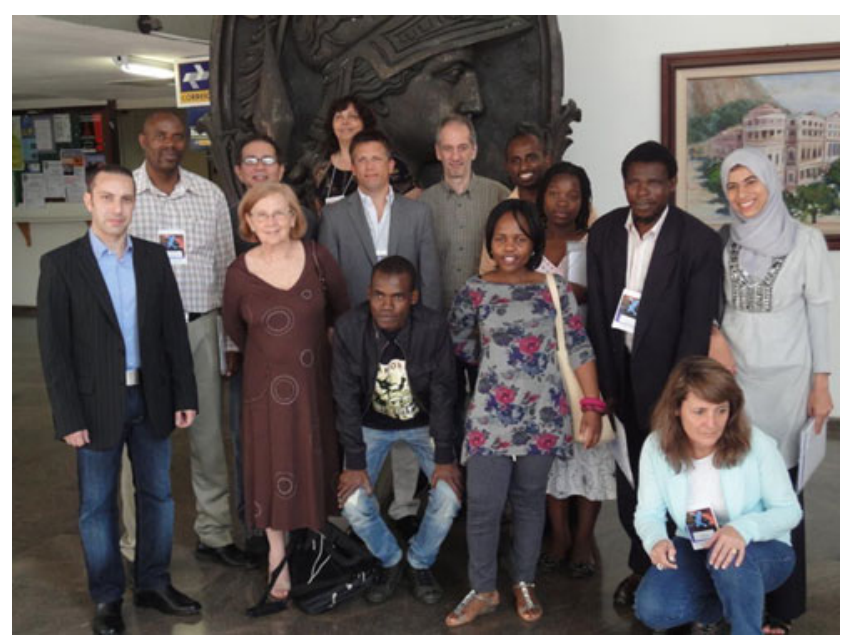

\section{From Gracinda Mondlane, Mozambique}

My journey to the Biophysics Conference began when I received the invitation to participate. First of all my questions was "what is biophysics and how is it related to physics and all of science?" It is true I had heard about biophysics before but I never properly understood the field, so this conference was a way to understand exactly what biophysics is.

First I will talk about the Conference. Patently the Professors were always there to explain every doubt we had and to answer all our questions. For me, everything presented was new and I had an opportunity for discussions with the students from Brazil and others from Africa. Also, the professors were always available in the University or in the hotel where we stayed.

For the first time, I realized there is a very simple way to discuss science in general and biophysics in particular. One of the purposes of the meeting was to establish cooperation between students from Africa and Latin America, and in my view this objective was achieved. I learned the way that Brazilian scientists make science. It is really interesting to have students working to reach results with the help of teachers who act as facilitators in the process of learning and teaching. In this regard Africa, particularly Mozambique, has a lot to learn if science is to develop.

In this way I was introduced to biophysics, and I got to see the multi-disciplinary nature of biophysics. Really now the main fields of science are coming together for the benefit of all humanity.

Some aspects of biophysics are in my field of knowledge, such as the Environmental Biophysics (that is included in Medicine in Mozambique) and Nuclear Magnetic Resonance (NMR). Despite having never used NMR to determine protein structure, we used this spectroscopic method to measure oil content in some seeds and to control the quality of some food and drinks. Unfortunately, we did not have a visit to an Environmental Biophysics laboratory, which I think would have been of special interest to me. The laboratory visits were to me the most important part of the Conference. I had the chance to work in a practical way with some $\mathrm{PhD}$ and Masters students. That was really amazing. In the labs I really got to see how things are done! It was interesting to see how protein structure is elucidated using NMR or by the use of Informatics (that was the best part!!!). I am thankful especially to Helen Jannisy and her collaborators. It was really nice to share some moments together. Thanks also to $\mathrm{PhD}$ student Marcius Almeida and the Bioinformatics team. Another very important opportunity I had was to pay tribute to the one that gave a hand 
to Biophysics in Brazil and in the world in general. I refer to Carlos Chagas Filho. It was special to me to visit the room that used to be his. Thanks to the organizers who made it possible for me to have this special experience. We are making efforts to establish a biophysics course here in Africa, but as the professors said, we still have a long way to go to this end. We hope to get a helping hand from Brazilian scientists and experiences in the future. To finish my report, it was really nice and interesting to be in Rio de Janeiro, a beautiful city to be remembered for my lifetime.

I will always remember the beaches, the wonderful people and the good times I had there. I wish I could be there once again.

$* * * * * * * * * * * * * * * * * *$

\section{From Anley Tefera, Ethiopia}

The Biophysics workshop was divided into two parts. The first (August 30-September 3) consisted of various lectures by professors from all over the world in various fields. The second part (Sept. 6-10) consisted of rotation in various laboratories at the university to learn different techniques. This report is a short reflection of my two-week stay and my overall experience. It also includes what I have gained from the workshops, and some suggestions.

My stay in Rio de Janeiro was one of a kind. Copacabana beach is beautiful and sightseeing at places such as Pan de Azucar was great. Participants in the course from Brazil, Argentina and Venezuela were very friendly. I also had the chance to meet and discuss various issues concerning Africa with other African participants.

The course was broken into several symposia, given in the first week of the workshop. They were truly amazing. I was able to take part in a course where some of the best scientists in the world shared their findings. In each symposium four or five investigators presented their current work, starting from the basic concept of their study. I was introduced to many new concepts, techniques and novel ways to solve problems. For example, I thought it was very clever of one investigator to study flux of water through water channels by looking at volume change. It just shows how it is possible to think of more than one way to solve a scientific problem. In the second week, various groups at the university allowed us to learn various techniques in their laboratories. The prior exposure to these techniques varied among the African participants, but it is safe to say almost all were new to $90 \%$ of us. For myself, even though I had heard about AFM and NMR before, I had not seen the actual equipment.

Three days were not enough to master any of the techniques, but we were introduced to their basic operation and their importance as a tool to solve science problems. We were also able to have some hands-on experience, where we were actually in the driver's seat operating some of the machines.

Before we, the African participants, left Brazil, we discussed the possibility of hosting a biophysical event in Africa in the near future to encourage growth of the field on that side of the world.

Since our return home, we had some preliminary talks along the same lines. We believe that the spreading Brazil's wings to reach Africa is a very historic gesture, and the start of something new. Customarily, help and collaboration flow from the northern to southern hemisphere. But this act by Brazil will encourage lateral diffusion of co-operation in the southern hemisphere.

I am so grateful to be one of the selected participants, and I would like to thank the organizers, IUPAB and LAFeBS, and the sponsors, ICSU, IUPAB and the Brazilian government. Special thanks to LAFeBS President Dr. Marcelo Morales and his team for their exceptional kindness, hospitality, and for organizing such a wonderful course.

The best professors from all over the world, and the various laboratories, shared their time and knowledge, so many thanks to them also. Last but not least, I wish to thank all who made my trip possible and enjoyable including the African Office (ROA) and my fellow participants.

Suggestions The inclusion of African students in such a course is a very noble idea, and I hope this collaboration between the two continents will continue in the future. I believe it is beneficial to sponsor selected students from Africa to study in Latin America. The two-week course is exceptionally useful in introducing topics and techniques, but it will require lengthier studies and collaborations to make fast strides forward.

\section{From Henry O. Otunga, Kenya}

My nomination I was attending a job appraisal interview at my place of work, Maseno University, Kenya when I was nominated for inclusion in the program. The selection panel had the chance to peruse my $\mathrm{CV}$ and my $\mathrm{PhD}$ details. Later that evening I had a phone call informing me that I had been nominated and urging me to put forward my application to the organizers.

My first reaction Since childhood, I had known of Brazil's prowess in soccer. In my country more than $90 \%$ of soccer lovers are fanatical followers of Brazilian soccer, myself included. Kenyans are passionate about famous Brazilian players such as Pele, Ronaldinho and others. Therefore, when I was invited to travel to Brazil, it was the opportunity of a lifetime. It had never crossed my mind that one day I would travel to Brazil. Furthermore, Brazil is my first destination outside Africa. 
Organization Contact with the organizers by email was prompt and efficient, and they were very understanding. On arrival in Sao Paulo I was met and ushered smoothly through. In Rio I was met by an official who identified himself before whisking me away to my hotel in a saloon car. The coordination was superb. Accommodation, shuttle services and food were simply excellent. I have attended conferences in Nairobi, Kenya and Dar es Salaam in Tanzania. In terms of scope and organization, the Brazil conference was unbeatable in many aspects.

The course Presentations by invited speakers were very detailed, of high quality and inspiring. I believe this shows the competence of South American scientists. I was especially mesmerized to discover how important a role physics and chemistry play in the understanding of the properties and interactions of proteins (biology). I concluded that at the molecular level, biology, physics and chemistry are not distinct but complement each other.

Equally impressive, in terms of content and appearance, was the quality of posters during the poster session. The number of students who turned up was relatively good, not to mention the gender balance, which was satisfactory. A walk through university laboratories gave me the chance to learn about some equipment I had never seen before. I especially remember the NMR equipment. What did not escape my notice is the high quality of research being conducted. This is vindicated by the fact that many of the researchers based there have publications in internationally renowned journals such as Nature and Materials Today.

Science in Brazil Thus, I conclude that Brazilian science is going places. Brazilians are simple, happy and sociable people despite the challenges they might be having. During my two-week stay, I don't remember ever meeting a depressed Brazilian. People are always smiling and taking it easy. The infrastructure is impressive. The road network, public transport system, seaports, airports, bridges, underground tunnels etc... were just great. I also visited some tourist attractions such as The Christ and the Rio Museum. Given another chance to visit Brazil, I would not hesitate.

Thank you.

(Henry is at front right with other students.)

$* * * * * * * * * * * * * * * * * * * * * * * * * * * * * * * * * * * * * *$

\section{From Clement Shonhiwa, University of Zimbabwe}

I was the only representative from Zimbabwe. There were two South Africans, two Mozambiqueans, two Ethiopians, one Kenyan, and one Moroccan. All had strong backgrounds in Physics, Chemistry, Mathematics and Biology. The majority had either $\mathrm{PhD}$ or Masters degrees from their respective countries. The conference was in 3 major parts: i) oral presentations of scientific papers; ii) Poster presentations; iii) practical laboratory sessions by African participants.

The presentations were generally of high quality and were presented by those seasoned in biophysics. The selection of presenters was fairly good but I think at least one or two from the African continent should have been included. Timing was generally good but inadequate for discussions afterwards. Personally, I was very impressed by the quality of presentation from Prof. Burns C. Blaxall (Univ. of Rochester USA) and Luis Costa of Petrobras (Brazilian Petroleum Co.). They clearly spelt out how to link the scientific and industrial worlds. I think this gap should be reduced. Indeed, there should be a bridge where research results are taken by industrialists for the betterment and development of humankind. In these two presentations, I learned how to transfer my research work into industrial work.

There were 120 posters presented and these were categorized into 6 classes: Biophysics and new therapies; Biochemistry applied to biophysics; Cell signaling, cell physiology, gene expression, channels and transporters/ receptors; Biophysics and physiology; Protein structure/ folding/modeling. Of these, four were presented orally and there was also a selection for the best posters, one of which was from Africa. We were all happy about the selection. The posters were generally of good quality and it was a good lesson to some of us. Hopefully we shall implement the lessons we learnt and in the future we shall improve our own work.

The practical laboratory session was only attended by students from Africa. The students had a series of practical lessons in which we were taught how to use some state-ofthe-art analytical laboratory equipment ranging from gas chromatography to more sophisticated digital NMR in biomolecular and pharmaceutical research. We learnt that the Institute is well equipped and has qualified personnel for research in biophysics. Our exposure to this state-of-theart equipment was really an eye-opener.

We were all well satisfied and agreed that, given the opportunity, we should produce a lot of published papers through collaborative research.

Social aspects The delegates at the workshop were very social, especially the students and the university staff. We from Africa easily incorporated ourselves into the Brazilian university society because of its high degree of hospitality. During weekends we were taken to some tourist places where we were able to intermingle with the wider Brazilian community. My observation was that Brazilians are 
generally friendly and I hope this would be the same in the African society.

\section{Concluding comments}

Apart from asking the participants, perhaps the best, even the only way to assess them is measure benefits over time. The above comments by the African students were reflected in comments from the students from Latin America. We can see new friendships have sprung up. It is also clear that the experience was a real eye-opener on both sides of the Atlantic.
The authors feel that we have sown the seeds of new understanding and new respect between the two regions. Brazil is clearly capable of providing resources for advance scientific cooperation and understanding. If the students involved maintain the enthusiasm they displayed in Rio, it will rub off on their fellow students as well as their professors. It is true that the experiment was quite expensive (about euro5,000 per student), but we believe it was not only worth it, we think it should be repeated with a different group from different African countries. With the benefit of some organizational hindsight, the costs should come down and the benefits should go up. It would be a small price to pay for the improved understand achieved by the workshop, particularly as many of the students today will become the leaders of tomorrow. 